\title{
Evaluation of Radarsat multitemporal data for crop discrimination in highly cultivated areas
}

\author{
Maurício S. Simões, Antonio R. Formaggio, José C. N. Epiphanio, Corina C. Freitas \\ National Institute for Space Research (INPE) \\ Av. dos Astronautas, 1758, Cx.P. 515, 12227-010, São José dos Campos, SP, Brazil \\ Phone: +55 12-345-6472; fax: +55 12-345-6460 E-mail: simoes@ltid.inpe.br
}

\begin{abstract}
The aim of this paper is to evaluate the potential of Radarsat fine mode multitemporal data for crop discrimination and monitoring. The test site is an intensively cultivated region in São Paulo State, Brazil, which has various classes of land use, such as sugarcane, pastures, corn, potato, tomato, fallow fields, beans, urban area, water, bare soil, and natural vegetation. Radarsat F4 data from Jan/05/98, Fev/22/98 and Mar/18/98 were calibrated to produce a multitemporal composion and to extract the backscattering coefficient. Backscattering values statistical analysis produced confidence interval for each class of land use. The statistical analysis and the graphical profile of temporal variation of backscattering of crops presented a significative separability between crops using the multitemporal information. The best single date to discriminate crops was January because of better differences in the phenological stages of crops in the test field: corn starting the ripping, sugarcane still in the vegetative stages, tomato in the early stages, pasture with high biomass, beans in the early stages, bare soil tilled (rough) and summer fallow. Differences in the soil cover, plant height, plant density and crop growth stage contributed to decrease the separability of crops in the same class of land use.
\end{abstract}

\section{INTRODUCTION}

Crop discrimination is an important application of satellite data. However, mainly in tropical regions, the use of orbital optical data alone is hampered by the high probability of cloud affected data. Indeed, cloud cover problems during some crucial periods of crop development have caused serious difficulties for crop monitoring. Thus, the objective here is to evaluate the potential of Radarsat fine mode multitemporal data for crop discrimination and monitoring.

\section{DATA SET AND TEST AREA}

The ground data used in this study were collected near Sumaré, São Paulo (S $22^{\circ} 54^{\prime} 52^{\prime \prime}$ to $22^{\circ} 47^{\prime} 40^{\prime \prime}$ and W $47^{\circ} 20^{\prime} 23^{\prime \prime}$ to $47^{\circ} 20^{\prime} 16^{\prime \prime}$ ), on three fieldworks during the summer of 1998 (03-06 January, 20-23 February, 18-20 March). The test site covers a watershed with $16 \mathrm{~km}$ (North-South) by $12 \mathrm{~km}$ (East-West) and it is almost entirely covered with crops. In January the field crops were sugarcane ( $45 \%$ of the fields), corn $(33 \%)$, pasture $(22 \%)$, bare soil (16\%), tomato (12\%), summerfallow $(9 \%)$, cotton (3\%). In February appeared fields with beans and tilled. fields prepared for tomato. In March some areas of corn were harvested and areas with straw started to appear.

The Radarsat SAR data, operating at C-band $(5.3 \mathrm{GHz})$, HH polarization, were collected and processed by CCRS in the fine mode descending pass in January 05, February 22. and March 18. All of images were acquired in beam $4\left(45^{\circ}\right.$ incidence angle), with 1 look and $8 \mathrm{~m}$ of azimuth resolution.

Two digital processing methods were used. One concerning the visual qualitative analysis and another one emphasizing the quantitative analysis and the separability between crops.

For qualitative analysis, the images were calibrated, orthoretified, co-registered in order to produce a multitemporal composition. The composition was filtered with a 3 by 3 median filter to reduce the speckle noise and to increase the visual properties of the images. In the quantitative analysis the digital image processing involved the calibration of the images in order to permit the extraction of the backscatering coefficient $\left(\sigma^{\circ}\right)$ in $\mathrm{dB}$ values. 


\section{ANALYSIS OF RADARSAT DATA}

A quantitative analysis was carried out using agronomic parameters collected during the field campaign, such as: detailed description of crop type for each field; crop growth stage; plant height; row direction and spacing, and percent ground cover. These data were supplemented by $35 \mathrm{~mm}$ photographs of the fields taken both on the ground and from an aircraft.

Figure 1 shows some fields studied in this paper. Field $\mathrm{A}$ is the only one cotton field, and appears bright in the 3 dates. This bright the radar backscattering of cotton is caused by the large flat leaves acting as differential scattering centers and the row direction of this field, which is perpendicular to beam direction [2]. Fields $B$ are sugarcane fields, in differents growth stages. Field $\mathrm{B} 1$ is an area of center pivot with low percent of ground cover in January, presenting low backscattering due to the interference of low soil background backscattering [3]. Fields $\mathrm{C}$ represent corn areas. $\mathrm{C}$ is a field of central pivot with corn in the flowering stage in January and ready to be harvested in March. It is possible to observe that in the flowering stage the backscattering was lower than in February and March, because in the flowering stage the backscattering is dominated by heads which have great attenuation in the rippeing stage the corn canopy presents a lot of gaps, increasing the roughness and the backscattering. When fields B (sugarcane) and C (corn) have 100 percent of ground cover they presents similar backscattering characteristics, because the closed canopy dominates of the signal backscattering. Field $\mathrm{D}$ and $\mathrm{E}$ are pasture and summerfallow, respectively. The pasture fields are areas with low backscattering in all three dates. The summerfallow fileds have their behavior dependent of the roughness and percent soil cover. When roughness and percent of over are small the backscattering is very low, as can be seen in E. But when roughness is high and weeds cover the soil the backscattering increases. The $F$ fields are areas tilled for tomato in January and Tomato in the subsequent images. The main factors that influence tomato backscattering are the presence or absence of vegetation and the row directions. If row direction is perpendicular to the beam direction, the signal is high. If the row direction is aligned with beam radar direction the signal is low. As tomato grows, the signal for field with row direction perpendicular to the beam direction decreases, and for the field with row direction parallel increases. In march the difference both fields is decreased, yet different.

The quantitative analysis was based on $95 \%$ confidence intervals to estimate the potential to discriminate crops by the mean of backscattering signal of each field [4]. This was done for two fields in each land use class. Figures 2, 3 and 4 show the multitemporal variation in backscattering in the three dates. It can be seen that there is a strong similarity between radar backscattering for corn and sugarcane when this two crops are with high biomass and cover $100 \%$ of the soil. Near the harvest the differences between these crops become bigger and they can be discriminated from each other, as can be seen in March. The tomato fields were significatily different from other crops. Among tomato fields there were differences caused by the row direction in all three dates. The above ground vegetative biomass is an important factor on reducing the effects of row direction, row spacing, soil roughness and moisture. Cotton could be discrimate in all 3 dates, basically because of its architecture, leaf size and geometry, and row direction, summerfallow had a similar mean backscattering coefficient of sugarcane, corn and pasture.

Comparing the dates for the possibility to separate crops, January was the best. In this image there were confusion between some fields of corn and sugarcane, and dense summerfallow, corn and pasture. These results can be explained by the differences in the crop calendar of these fields.

\section{CONCLUSION}

The aim of this study was to investigate the use of Radarsat data for crop discrimination and monitoring. The approach included the analysis of the radar backscattering of crops as in relation to some biophysical parameters. As expected, the radar backscattering of crops exhibits significant variation as function of plant high, soil cover, soil roughness, row direction and phenological stage. The similarity of some parameters decreases the possibility of discrimination between high biomass crops like corn, sugarcane, dense summerfallow and pasture. Crops in the early stages, due to the dominant soil backscattering, presented similar values. 


\section{ACKNOWLEDGMENT}

The project is part of GlobeSAR 2 - project 22 and the RADARSAT images were given by Canadian Space Agency and Canadian Centre for Remote Sensing.

\section{REFERENCES}

[1] R.J. Brown, M.J. Manore, S. Poirier, 1992. Correlations between $\mathrm{X}$-, C-, and L-band imagery within an agricultural environment. International Journal of Remote Sensing, Vol. $13, \mathrm{~N}^{\circ} .9,1645-1661$.

[2] C.S.T. Daughtry, K.J. Ranson, L.L. Biehl, 1991. C-band backscattering from corn canopies. International Journal of Remote Sensing, Vol. 12; $N^{\circ}$ 5; 1097-1109.

[3] F.T. Ulaby, C.T. Allen, G. Eger, E. Kanemasu, 1984. Relating the microwave backscattering coefficient to leaf area index. Remote Sensing of Environment, Vol. 14, No 1$3,113-133$.

[4] G.M. Foody , G.B. Curran, D.C. Munro, 1989. Multitemporal airborne synthetic aperture radar data for crop classification. Geocarto International, Vol. 4, $\mathrm{N}^{\circ} 3,19-29$.

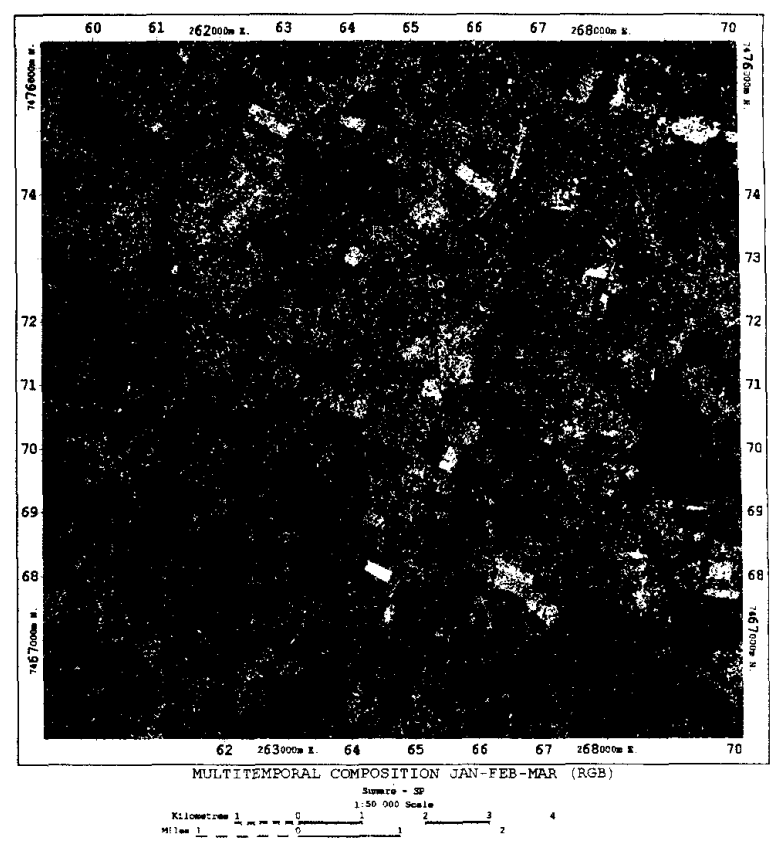

Fig.1 - Multitemporal composition Radarsat F4D.
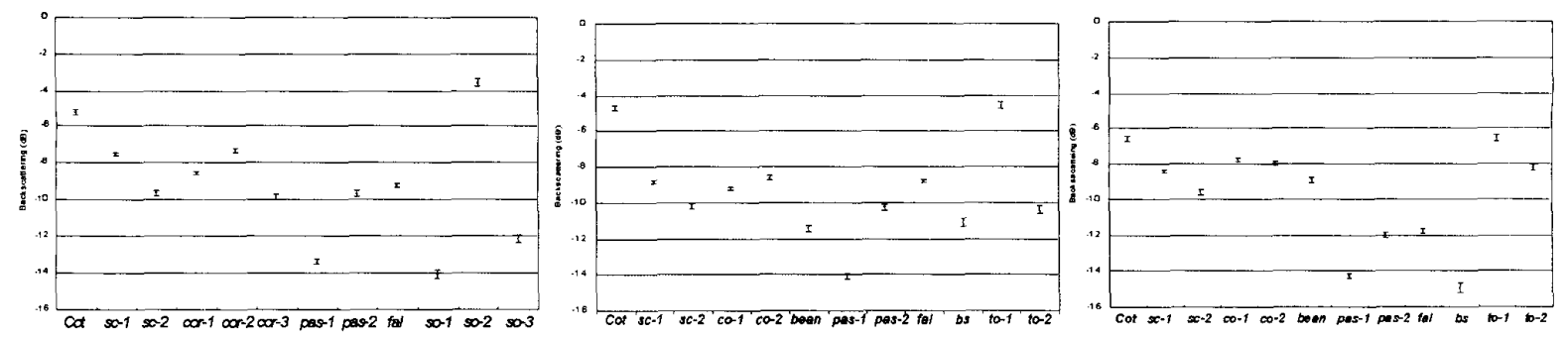

Fig. 2, 3 and 4 - Mean and standard error of the mean of $\sigma^{\circ}$ from January, February, and March, respectively. 